Revista Aspas

ppgac - USP

Entre Aspas

\title{
O COMPLEXO DE PENÉLOPE
}

\author{
THE PENELOPE COMPLEX
}

EL COMPLEJO DE PENELOPE

Daniel Manzoni de Almeida

Daniel Manzoni de Almeida Doutorando em Teoria e História Literária pelo Instituto de Estudos da Linguagem (IEL), Universidade Estadual de Campinas (Unicamp). É professor, pesquisador de Ciências e escritor. Nome artístico: Daniel Manzoni. 


\section{Resumo}

Neste conto exponho a história de Eliseu: um jovem de classe média alta, cisgênero, branco, homossexual e profissionalmente reconhecido. Aparentemente, bem-sucedido aos padrões da estrutura da sociedade brasileira. Porém, ainda falta um amor em sua vida. Na busca desse relacionamento, Eliseu é como o mito de Penélope, na Odisseia de Homero, subvertido: em vez de esperar, procura por seu amado construindo no dia as possibilidades de uma relação, mas a destruindo à noite com facilidade o pouco que construiu, sempre na busca de uma felicidade pautada nas normas de uma sociedade heteronormatizada e sem referências claras de amor-gay.

Palavras-chave: Literatura LGBT; Conto LGBT.

\section{Abstract}

This article presents Eliseo's story: a young man of the upper middle class, cis-gender, white, homosexual and professionally recognized; apparently he succeeded according to the structure standards of the Brazilian society. However, he still has not found love in his life. Looking for a relationship, Eliseo is like the myth of Penelope, in the Homer's Odyssey, subverted: instead of waiting, he searches for his beloved building, day by day, the possibilities of a relationship, but easily destroying by night the little he has built, always searching for happiness based on the norms of a heteronormative society and without clear references to gay-love.

Keywords: LGBT Literature; LGBT Short Story.

\section{Resumen}

Esta historia muestra Eliseo: un joven de clase media alta, cis-género, blanco, homosexual y reconocido. Aparentemente, exitoso a los patrones de la estructura de la sociedad brasileña. Pero falta un amor en su vida. En la búsqueda de esa relación, Eliseo es como el mito de Penélope, en la "Odisea" de Homero, subvertido: en vez de esperar por la llegada del amor, busca por su amado construyendo, en el día, las posibilidades de una relación, pero destruyendo, por la noche, con facilidad lo poco que construyó, siempre, en la búsqueda de una felicidad en las normas de una sociedad de cultura heterosexual y $\sin$ referencias claras del amor-gay.

Palabras clave: Literatura LGBT; Cuento LGBT. 
Amantes meus depois de morto Ulisses, vós não me insteis, o meu lavor perdendo, sem que do herói Laertes a mortalha toda seja tecida, para quando no longo sono o sopitar o fado: nenhuma Argiva exprobre-me um funéreo manto rico não ter quem teve tanto - estas desculpas ingênuas aceitamos. Ela, um triênio, desmanchava à noite à luz da lâmpada o lavor diurno; ao depois, avisou-nos uma escrava, e a destecer a teia a surpreendemos: então viu-se obrigada a concluí-la.

(Homero, Odisseia, Livro II)

Dia. Talvez o que mais me excita não seja o final, mas a tentativa de sentir o gosto entre o que eu espero e o que realmente é. Nosso dating no aplicativo de pegação foi por acaso. Naquela noite eu acho que não queria nada com ninguém, mas estava tão enfadado de mim que procurei conhecer alguém. Estava tão cansado de mim, tão cansado do job, que eu só queria dormir. Mas não dormi: o sono não iria me restaurar; desejar outro, sim. Noites e dias trocados por conta do fuso horário de dias e mais noites de viagem pela Europa a trabalho, meu trabalho como stylist de uma marca mais do que famosa. Reuniões e mais reuniões de dia. Boates e mais boates à noite para aproveitar, para não ficar em silêncio e me consumir sozinho longe de casa. Paris, Roma, Berlim, Londres. Quando eu imaginaria essa noite esquisita, que já não sabia mais se de verão ou inverno, nesta cidade esquisita que não sei se é minha, São Paulo, ou se quero que seja minha de verdade. Parece ter tudo que alguém da América Latina pode querer, mas doce ilusão quando se ganha e conhece o mundo, tudo por aqui fica boring. Mas é para onde sou obrigado a voltar sempre, porque me é daqui o pó da terra dos meus pés e, no final é daqui que meu coração chacoalha, mesmo infelizmente, e é aqui que dialogo e consigo responder à pressão de quem eu sou e me esmago entre minhas perguntas e minhas respostas, e foi aqui que minhas mãos que cortam tecidos aprenderam a lidar abaixo de nomes pejorativos de veado e bicha, com as tesouras que hoje me levam ao mundo. Jogado no sofá, estava eu deitado tentando dormir por volta das dezoito horas, achando que já era mais de meia-noite, mas o cheiro fresco do entardecer me lembrou de que não chegou a hora do perfume da dama-da-noite no calor do verão, quando entrei no aplicativo e dei match com um boy que tinha tudo, correspondia em absoluto o que eu queria naquelas fotos, como um prato de comida, uma 
roupa, um CD, um livro: bonito, másculo e nada afeminado. A foto dele mostrava o que qualquer gay poderia traduzir como um homem hétero. Dias e mais noites, noites que mais pareciam dias, dias que mais pareciam noites de tão esticadas na sensação embriagada de sono que eu, encantado, conversava com ele. Renan o nome dele, sim, o nome do meu homem a partir de então. Cada vez mais encantado, queria conhecer ele e ele me conhecer, nos falamos por telefone, horas intermináveis, chamadas a qualquer hora, e nos vimos por câmera, na chamada ao vivo do aplicativo. Não foi a mesma coisa, porque eu mais perdi tempo disfarçando que prestando atenção no que conversávamos, eu só queria parecer bonito, eu só queria parecer mais másculo e perder minha afetação. Beleza, não era só minha preocupação. Na verdade, não sou bonito, eu não queria parecer feminino, odeio minha voz que não é grave: de tão aguda, quase quebro os cristais da esperança quando falo. Vergonha mesmo também da minha forma de falar, gesticulando, virando uma mão com a outra virada no quadril, não posso fazer isso no nosso primeiro encontro. Sempre me apontaram esse meu jeito: eu detesto. Sempre estiveram certos. Eu menti para o Renan, mentira sincera, mentira do bem, mentira necessária para não parar o mundo, não! Mentira para enganar mesmo, eu queria enganar ele como uma sereia que canta para atrair e afogar. Era isso: no meu mundo é a minha verdade, então, falei minha verdade. Foi quando ele me perguntou se era afeminado. Disse que não logo na lata, não hesitei, já perdi encontros antes por conta disso, os caras não gostam de caras afeminados, yes, no pain. Por mais que eu seja passivo, isso não quero falar, é vergonhoso, que fica entre quatro paredes, ninguém precisava saber logo de súbito, de súbito já basta a morte, na vida é coisa lenta para não doer mais do que o necessário e impedir a mentira que se fala para flutuar, o importante é flutuar na magia, o resto é verdade para a morte súbita. Na verdade verdadeira, sem magia, não dá para ele apresentar o cara afeminado para a família. $O$ duro de ser gay não é ser gay, porque se é e pronto, mas não dá para suportar não ser amado por ser quem se é e, além do mais, não ser atrativo. Eu quero ser desejado por um homem do mesmo jeito que ele deseja uma mulher. Então disfarcei todo esse tempo, semanas conversando, enrolando para um encontro, e chegar até Renan, tão másculo que nem parece gay, que nem me permito mais perceber os desvios de sua masculinidade, que nem mais é o 
Renan verdadeiro, é o meu Renan. E o perigo dele não querer nada comigo por eu ser afeminado. Seria uma possibilidade. Seria uma possibilidade? E o mundo que criei até então? Minha família só ficaria orgulhosa de mim se ele fosse másculo, fora do meio. Dentro do meio heteronormativo. Já basta eu de afeminado. God!, é apavorante só de pensar que isso pode acontecer, é apavorante não ser o que esperam, é apavorante não conseguir nem o que esperam, ficar na linha de chegada, plantado, até percebi o olhar de reprovação do motorista do táxi ao me ver. Escolhi para esse encontro a camiseta de cor não chamativa ao invés das camisetas de estampas que gosto, vesti um jeans mais solto ao invés do mais colado como me agrada, tudo para Renan me querer. However, e se ele for afeminado? Será que eu vou querê-lo? E se ao invés dele tomar o susto comigo, eu, Eliseu, tomar o susto com Renan e ele for o afeminado? Eu teria vergonha dele. Tenho certeza que ele não é feminino. Na verdade, serei eu que vou perder o tesão, porque sou eu que não gosto de cara afeminado. E eu já estou planejando tantas coisas para nós dois, até casa com cachorro na minha imaginação temos, será que minha família irá gostar do Renan? Será que a família do Renan, se ele for assumido, nem conversamos sobre isso, God!, nem sei se família ele tem. O que só me importei esses dias todos foi que ele fosse como eu quero que seja, para eu não ter que escondê-lo e poder me esconder, derretido, dentro do mundo dele que eu quero. Mas já construí uma história toda para nós, porque é assim que tem de ser: eu serei a mulher e ele o homem, como qualquer família que conhecemos, não aceitarão outro modelo. Se quiserem saber como somos, somos assim. Eu já disse a ele que tenho vontade de passar a lua de mel do meu casamento na Patagônia, não conheço lá, mas deve ser um lugar mágico na América Latina, um dos poucos depois de ter conhecido a Europa e os EUA. Não quero continuar a morar na Bela Vista, como moro, disse que assim que casar quero mudar para Moema, vários casais de amigos meus gays moram em Moema, bairro residencial e que tem muitos casais gays. Passagem digna de vida. E esse táxi está demorando muito para chegar ao shopping no Jardins, ainda cruzando a Avenida Paulista. Marquei em um lugar sofisticado para nosso primeiro encontro ser marcante e qualquer traço feminino meu ser diluído pelo encanto das luzes, brilho e beleza das vitrines das lojas. Só a beleza da moda dilui o desagradável de quem se é e não se gosta. A moda exige 
aprovação dos outros, e eu dependo disso, sou escravo do que acham e querem de mim. Ele disse que gosta de moda, fiquei feliz, pois imagina ele ter que conviver comigo, que trabalho na moda, e não gostar da moda? Ele parece ser bem vestido, vestido bem másculo, nada afeminado. Falta pouco e, por mais que esteja perto, sempre me vem a sensação de querer fugir para bem longe e não concluir qualquer encontro. l'm a creep. Não mereço nada disso. O táxi parou em frente ao shopping, meu coração salta pela boca, eu pago e desço e não ando, não flutuo, me arrasto, rastejo como um bicho escorregadio achando que todos estão olhando para mim e me julgando como errado, é essa escravidão que vivo da moda: vão me trocar como trocam de camiseta; e lembro da minha mãe, que de dentro da minha cabeça tem vida própria e diz "Rapaz bonito, mas escandaloso demais", mas é uma avalanche que transforma meus sonhos em pesadelos, imagens projetadas de um romance belo na doce ilusão de ser enganado. Caminho escadas rolantes acima, ansioso, pulando degraus, passando pessoas devagar, o momento é meu: saiam da frente, o mundo, prestes a ruir, é meu; e negando ser levado por eles como de direito, e encontro Renan à minha espera com um sorriso receptivo que flecha meu coração culposo, liquefeito em fel que puxei para me ajudar a desistir e sacrificar meu desejo; enquanto isso, eu só queria voltar para casa, ir para casa dos meus pais e pedir desculpa: troco qualquer amor pelo de vocês.

Noite. Vivo minha rotina como vivo minha profissão: trabalho intensamente para criar uma coleção nova para cada estação do ano próximo e logo em seguida desfazer tudo para a próxima, um ciclo de fazer e desfazer. O encontro não foi o que eu esperava, Renan era outra pessoa que eu não esperava. Talvez eu não quisesse. Ele é gay, tão gay quanto eu, percebi logo no início. $\mathrm{E}$ eu não quero gay, eu quero hétero. Não atingiu o que eu havia imaginado, imaginado tão intimamente dentro de mim. Todas as imagens que eu havia criado sobre ele, durante todos esses dias de diálogos pelo telefone, caíram por terra nos minutos que seguiram o nosso encontro, fail. Eu quero o homem másculo que percebi naquelas fotos, naquela descrição do perfil, nas ligações que eu recebi. Ele era tudo que eu queria e agora é tudo o que eu não quero, estou em um desinteresse por ele tão melancólico neste momento, tão 
desanimador que não consigo classificar, mas apenas dizer que tem o gosto insosso e aguado, como uma mordida em um chuchu cozido, quando eu esperava morder uma maçã suculenta e adocicada. Eu procuro esse doce das frutas no amor, o açúcar natural impregnado nas coisas naturais e surpresas nas frutas da natureza, a emoção de morder o adocicado e poder flutuar na explosão de sabor. É isso que eu vejo o tempo todo entre os casais heterossexuais, é isso que eu quero para mim. Eu chego a odiar Renan instantaneamente e tão insuportavelmente que não aguento mais olhar para seu rosto, só queria ir embora, página virada, perfil do aplicativo apagado. Eu quero na verdade é o sabor da emoção, do encontro mágico daquilo que imagino ser a realidade, não quero a realidade que existe, quero a que imagino, se não tiver, vou desmanchar tudo como desmancho as coleções e partir para a estação seguinte. Quero a realidade que eu criei e não a que me jogam todos os dias para me lembrar que eu sou descartável e explorável: susceptível. É assim que um gay afeminado é: criança sozinha nadando em piscina funda. $O$ andar para frente, à espera do próximo, me faz sentir meu desejo vivo, desejado, sou consumo de mim mesmo. Por isso não dei esperança ao Renan, dei a realidade, que não o quero. Surpreso, ele encheu o olho de água e disse que não reconhecia o Eliseu das ligações, das mensagens de dias e noites, e eu disse que era assim mesmo: às vezes não bate, às vezes não acontece, o cheiro que a realidade próxima traz não tem o mesmo sentido da imaginação. Renan voltou para sua casa, e eu voltei à minha para recomeçar tudo outra vez, ainda vou encontrar um amor.

Ei leitor pretendente, venho contar a você o que vejo no clarão da noite, não se engane: Eliseu, nossa Penélope, espera um Odisseu que não voltará para Ítaca porque esse Odisseu não saiu de lá ainda. Criado e crescido dentro de uma ideologia, o Odisseu de Eliseu já nasce morto. O que faz de dia, desfaz de noite à espera do amor ideal que não vem porque nunca foi. Num ciclo consumista que consome seus amores inéditos na busca dos amores conhecidos, alheios, padrões que não Ihe pertence. Oh, Eliseu, a minha Penélope, que subverte o destino da espera e parte para a procura. Não espera seu amor chegar a sua ĺtaca, ele constrói uma ítaca e leva até seu Odisseu moldado na forma da heteronormatividade. 
Dia. A tendência para a coleção de verão desse ano está exigindo cores mais vibrantes, quentes, diferentes da coleção de inverno que acabei de lançar, dark, e eu estou cansado de tanto que trabalhei para buscar a coleção de inverno mais cobiçada da cidade, e porque não do país, e porque não do mundo, para agora, quase sem descanso ter que buscar outra coleção, desfazer todo o conceito que construí para construir outro conceito tão vivo e impactante quanto o anterior, construir e destruir faz parte do meu ser. Eu gosto da procura, mais prazer ainda em não achar e embriagar na esperança. Esperança é droga que faz dependente o desesperado preguiçoso. Nos encontramos em pouco tempo, entre a entrada do banheiro e o bar da pista de dança da parte de baixo. Ele, Diego, estava dançando desengonçado com uma garrafa de bebida cara de sabor limão na mão, estava bem vestido, corpo bem definido, logo notei, na certa tem tempo para frequentar academia, roupas verdadeiras de grifes, nada falsificadas, o que logo me fez perceber que não era um qualquer e me deu forças para investir. No escuro, investi com poucas palavras logo cobertas pelo essencial de um beijo e uma pegada no pau, para não acender muita intimidade naquele momento com palavras que muitos revelam. Deixamos a conversa para o dia seguinte e aqui estou eu, que mal dormi, por efeito da ansiedade de reencontrá-lo e do efeito do doce que tomei de suas mãos e de sua saliva, entre o azedo de sua bebida e a doçura da promessa de um romance que aqueles beijos no escuro, ao canto do bar, me prometiam. Whatever. Ele, Diego, tinha potencial para ser meu namorado: másculo e de um aparente status social não recusável. Usava perfume bom, conhecido e importado, o que confirmava minhas expectativas. Disse que falava outras línguas fora o inglês que todo mundo fala. Fora o celular que era do melhor. Corte de cabelo também. Perguntei a profissão antes do primeiro beijo, entre a pergunta do nome e a pergunta do bairro em que morava, Moema, meu sonho, e não dividia apartamento e muito menos estava com os pais. Do resto foram apenas beijos. Beijos a noite inteira, naquele canto da boate, que me levaram para as melhores sensações, para o grande caminho de um bom relacionamento que já tinha sido feito. Não iria me envolver com qualquer um, mas com um advogado empresarial como Diego com certeza, provavelmente lidava com problemas interessantes do empresariado, não era advogado trabalhista, os problemas eram o que me interessavam. Será 
que ele quer namorar comigo também? Não seria um louco se quisesse, um stylist como eu, bem-sucedido, não sou uma bichinha qualquer que trabalha em lojas de departamento de roupas, estou acima da faixa do preconceito, tão acima que sou o orgulho da família por ter dinheiro e mais dinheiro cada vez mais. Imagina o orgulho que minha família deve ter de mim, por eu estar cada hora em cada canto do mundo; eu só queria dar orgulho à minha família e dei pela parte mais fácil de aceitarem, pelo dinheiro. $\mathrm{O}$ dinheiro me abriu portas na família, meu cartão de visitas é meu poder de compra diante da minha família. Com certeza será diante de Diego também. A felicidade que procuro pode ser comprada, tenho certeza disso, como dois e dois são quatro. Se eu não tivesse o dinheiro que tenho hoje, já teria sido abortado da Terra. O dinheiro que fiz e faço me mantém mais vivo que o material, é a minha existência mais profunda, graças ao meu pink money. Cheguei ao café na Avenida Paulista em que marcamos e lá estava Diego, com óculos escuros importados, sorriso tão receptivo que apagou o meu no bater do meu coração culposo. Cada passo que eu dava era tortuoso porque eu sentia os olhares de reprovação de quem estava à volta, eu sentia vergonha de mais uma vez estar ali, de mais uma vez ser quem eu sou, eu só queria voltar para casa e tudo aquilo acabar, eu queria pegar o telefone e falar com meus pais que tudo iria ficar bem, queria chorar, e chorei ao abraçar Diego, que já havia me dito que não gostava de problema, que a vida é alegria. Eu sabia que ali tudo já havia acabado antes mesmo de chegar o primeiro café expresso fumegante.

Noite. Voltar no metrô em um domingo à noite passado das dezenove horas, em São Paulo chuvosa, é melancólico. Eu sinto a exaustão do domingo nesta cidade que amanhã já estará toda de pé, espremida nos vagões e nos ônibus, tão sonolenta que dá dó. Mas ninguém sentiria dó de mim ali naquele momento com o coração despedaçado por não ter conseguido acender a chama do amor mais uma vez. Foi tudo tão rápido que não entendi, só sei que eu na verdade não sei mais se quero algo com o Diego. Ele é muito mais acima do que eu esperava, muito mais bonito no claro do dia, muito mais rico que eu poderia imaginar, não poderia competir com esses talentos que não tenho. Eu senti que ele era melhor do que eu quando me segurou aos prantos pelo braço, quando eu disparei a tentar 
falar em alemão e ele não entendeu nenhuma palavra e ainda corrigiu duas ou três frases, não lembro direito, com o idioma perfeito de quem morou por alguns anos em Berlim. Diego era melhor do que eu, esse é seu defeito que faço questão de afastar de mim. Não sei lidar com o melhor do outro, pois o melhor sempre está em mim. A vida não segue em quadros de cinema, então, não conseguiria lidar com os intervalos entre uma cena e outra do filme que eu criei, em que o melhor do outro vai aparecer fora do meu controle. É o jogo da convivência que a relação exige e não sei jogar, não tenho modelo, meu modelo é o de um homem e uma mulher e não o de dois homens. Defeitos masculinos irão se potencializar e ninguém fala sobre isso, ou se fala busca o que já existe, e o que é que existe, God? Eu só quero chegar em casa para começar a separar as cores da próxima coleção. Prometo que serão mais arrasadoras que as da coleção passada. Mas qual foi a coleção passada? Eu não me lembro. Quem se lembra? Ninguém, na certa. Como é bom perder o passado e ter só ter o futuro como meta, pois o presente é real e doloroso demais no vazio deste vagão do metrô que me faz tão comum e insípido. Quero desenhar, quero criar, quero tecer, mas ainda não sei o quê. $O$ amor, talvez.

Eliseu, a Penélope subvertida da espera

que tenta tecer,

não a mortalha,

mas o amor;

na esperança da chegada

do que nunca foi

a esperar, esperar

o que não existe

o que não sabe

tudo é espectro, simulacro

de alguém que foi imposto;

Não tem modelo de representação

Eliseu desfaz o que poderia ser modelo

pois, quer o Odisseu que nunca partiu 
Dia. Pedi o carro pelo aplicativo para ir ao encontro do Marcos. Quinze minutos esperando foram o que me fizeram consumir a unha do dedo indicador até a carne viva quando arranquei um dos pedaços e o sangue brotou como água na mina, a latência da dor deu uma aliviada na dor da espera que não passava. Ele me enviou algumas nudes e realmente é lindo. Nos conhecemos há dois dias e não paro de pensar na possibilidade de ser feliz com ele. Ele é um príncipe. E eu preciso tanto de um príncipe, que concebi esquecendo o tempo necessário para construir um reinado. Não quero república, quero reinado, para apenas eu mandar sem interferências, não suporto interferências desde que me livrei da minha família que diz me aceitar. Acho que só com um príncipe, que de tão bonito no reinado que eu construí, aceitariam. A beleza derrete preconceitos. Os belos, os verdadeiramente belos não sofrem, tem passagem livre para viver. Por isso procuro a beleza para encantar minha família e vencer a batalha de não ser realmente aceito. Quero a beleza para me encaixar na sociedade, já que eu não sou belo, procuro o belo para andar comigo no caminho tortuoso e ser o meu facão na selva abrindo caminho com sua beleza. Marcos tem essa beleza que eu preciso, todos que mostrei a foto dizem isso e isso é o que importa: a opinião dos outros. Só a beleza dele para impressionar os outros e manter o silêncio que me é tão caro ao me apontarem na rua, me excluírem. O barulho é excludente, ele separa. O silêncio não, acalma, faz ficar tudo homogêneo sem questionar. É dessa paz que preciso e não encontro. É essa paz que vejo nos casais heterossexuais e não vejo nos gays, estariam ainda aprendendo? Ou não buscam a beleza no outro por ser um casal gay? Não tenho certeza. Só sei que Marcos pode ser um passaporte para a aceitação, um troféu da vitória, do meu desejo a ser consumado, meu Ser é o Ter de alguém, é isso que projeto ouvindo a música do carro que me transporta rua Augusta acima rumo à Avenida Paulista naquele entardecer, para encontrar, por mais uma vez, um pretendente. Marcos, agora um príncipe atestado para além de mim, invejado para além de mim. Mas não foi inveja que senti quando coloquei os pés na calçada entre a Avenida Paulista e a Rua Augusta no final do trajeto, foi desespero por mais uma vez não querer investir, meu coração culposo vai perceber alguma coisa que ele não quer perceber e vou desistir de tudo novamente, porque não é perfeição que quero, é apenas algo sem brilho e com cheiro forte. O problema sempre é o 
cheiro que não está na imaginação. Ele que bota meus pés no chão e me diz a verdade, porque é só o cheiro que é a realidade, os outros é só enganação. Marcos estava me esperando com um sorriso no rosto e eu cheguei com a desistência já em mãos. $\mathrm{O}$ corpo cansado e a esperança dilacerada em não querer perder mais nenhum minuto ali, há todo um arredor que vale mais a pena que o desejo de realmente ser amado, que foi queimado, consumido ali, numa fração de segundos. Aquilo já não era o que eu queria, Marcos já não era mais o que eu queria, uma relação já não era mais o que queria. Eu só queria voltar para casa. Voltar para minhas cores, meus desenhos, meus tecidos e criar na solidão. Tenho certeza que quando eu chegar em casa o que vou mais querer será voltar no tempo e estar ali com Marcos novamente. Prefiro abortar o momento antes que Marcos me aborte do seu. É o jogo e não quero perder. Prefiro a dor da desistência que a dor da perda. Ele não entendeu, mas eu entendi, e sofrendo com prazer disse não antes do assistir ao filme no cinema como combinado, antes do beijo tão imaginado, ganhar esse jogo era meu dever.

Noite. Eu não gostei das cores eleitas para a nova coleção, mas tive que aceitar porque na verdade eu sou empregado, nesses momentos caio na real de quão independente eu realmente não sou, e minha inteligência é só metal sugada como imã por uma empresa que finge aceitar minha sexualidade, mas se aproveita da minha necessidade de dar orgulho para meus pais para sugar minhas forças e minha inteligência. Poucos lugares aceitariam o afeminado que sou e não quero aceitar, é o meu medo de ser rejeitado que me leva a não persistir nas minhas cores e aceitar as cores que me são impostas. Minha inteligência está sendo tingida por cores que não fazem parte da minha alma, minha alma está tão escura, tão dark nesse momento que permito ser submetido que não consegui avançar na conversa com Marcos. O tão esperado encontro com um príncipe virou um pesadelo, nenhuma frase saía da minha boca e arranquei mais um pedaço de unha do dedo polegar, que me trouxe uma sensação boa de alívio, mas fez Marcos saltar da cadeira assustado com o sangue que verteu e caiu na mesa do jantar esperado. Ali foi o desastre, porque eu não conseguia me desculpar, só comecei a chorar sem querer aceitar a cor vermelha imposta pela tendência e pelo lucro da empresa, no lugar dos 


\section{Daniel Manzoni de Almeida}

tons rosa e branco do meu reinado que queria dar à coleção. Enfim, eu estava tão apaixonado por Marcos naqueles dois dias de contato por fotos e mensagens eletrônicas que minha alma escura passou para rosa e branco. Fiz de propósito, joguei pra perder para não perder e fui direito para a casa dos meus pais, com o dedo enrolado em um pedaço de papel, na esperança de minha mãe perceber, para além do dedo, o machucado de minha alma, mas ela não percebeu. Sentei e assisti com eles a um filme de Hollywood. Pela primeira vez em meses, me senti em paz. Calado. Só falei obrigado quando meu pai trouxe pipoca para comer e não comi. A mão ficou ocupada com o celular e não pude apanhar a pipoca. Agora tudo estava calmo. Calado, meu desejo estava apagado. $O$ celular vibrou. Alguém gostou da minha foto. Seu nome era Bruno. Lindo, perfil perfeito, mas agora eu só queria pipoca.

\section{Referências}

HOMERO. Odisseia. Trad. Manoel Odorico Mendes. São Paulo: eBooksBrasil, 2009.

Recebido em XX/XX/XXXX Aprovado em $X X / X X / X X X X$ Publicado em 25/10/2018 